\title{
The General Factor of Personality (GFP) and Vocational Interests: a Test of Social Effectiveness at the Behavioral and Genetic Level
}

\author{
Dimitri van der Linden ${ }^{1}$ (1) Curtis S. Dunkel ${ }^{2} \cdot$ Eveline J. De Zeeuw $^{3} \cdot$ Peiqian Wu $^{1} \cdot$ Dirk H. M. Pelt $^{1}$
}

Accepted: 8 October 2021 / Published online: 8 November 2021

(c) The Author(s) 2021

\begin{abstract}
Previous studies have examined how personality models (e.g., Big Five, HEXACO) relate to vocational interests. We adopt a novel approach by testing the associations between personality and vocational interests from the perspective of the general factor of personality (GFP). One interpretation of the GFP is that it reflects social effectiveness. Based on this interpretation, we predicted that the GFP is particularly related to interest in social jobs because people generally tend to be attracted to activities in which they perform well. To test this, we used four large data sets: the Professional Worker Career Experience Survey (study 1a; $N=752$ ), OpenPsychometrics.org (study 1b, $N=108,209$ ), Project Talent (study 2; $N=81,130$ ), and the National Merit Twin Study (study 3: $N=1536$ in 768 twin pairs). In each sample, we presented the direct associations as well as the results after using control variables (gender and cognitive ability). In study $1 \mathrm{a}$ and $1 \mathrm{~b}$, the GFP particularly related to interest in social and enterprising occupations. In study 2, the GFP related to interest in working with people and was also associated with a range of occupational scales involving social aspects. In study 3 , the GFP only showed a consistent relation with social interests. This association was present at the phenotypical as well as genetic level. Notwithstanding some variation in findings across the different studies, the overall pattern seems to be in line with the notion that the GFP is positively associated with the preference for more socially laden jobs.
\end{abstract}

Keyword Vocational interests $\cdot$ General factor of personality $\cdot$ Social effectiveness $\cdot$ Heritability $\cdot$ Genetic correlation

In research on individual differences, vocational interests play an important role. Although such interests have typically received less attention than cognitive ability and personality, they are often considered to be the third pillar of individual differences (Chamorro-Premuzic, 2007). Initially, it was assumed that vocational interests mainly influence decisions regarding what to study or which occupation to enter. However, more recent research has shown that interests also relate to performance in one's chosen direction (Nye et al., 2012; Van Iddekinge et al., 2011). In general, interests have motivational properties influencing the

Dimitri van der Linden

vanderlinden@essb.eur.nl

1 Department of Psychology, Education, and Child Studies, Erasmus University Rotterdam, P.O. Box 3000 DR, Rotterdam, The Netherlands

2 Department of Psychology, Western Illinois University, Macomb, IL, USA

3 Department of Biological Psychology, Free University Amsterdam, Amsterdam, The Netherlands direction of activities, the level of energy invested in them, and the persistence in the activities. All three aspects are direct determinants of job performance (Su, 2012).

One question that has been the focus of a wide range of previous studies and meta-analyses is to what extent vocational interests relate to personality (Larson et al., 2002; Mount et al., 2005). Such studies showed that, for example, in terms of the well-known Big Five model of personality, openness to new experiences is relatively strongly related to interest in artistic professions and activities. Extraversion particularly relates to interest in enterprising jobs, whereas conscientiousness overlaps with interest in conventional types of jobs, characterized by well-structured, careful, and systematic activities. Vocational interests have also been associated with personality dimensions in other personality models, such as the HEXACO model (e.g., McKay \& Tokar, 2012).

In the present study, we aim to provide a novel contribution to this research area by directly testing the overlap between vocational interests and the general factor of personality or GFP, which reflects the shared variance of more 
specific personality dimensions (Figueredo et al., 2004; Musek, 2007; Rushton et al., 2008; Van der Linden et al., 2010a). Although the GFP has been the topic of many studies, the construct is still relatively new and often raises basic questions about its nature and relevance. Therefore, one reason for testing its overlap with vocational interests is that it may contribute to insight into the nature of the general factor. Specifically, it can be used to test the hypothesis that the GFP reflects social effectiveness (see below) by examining its relationship with interest in social occupations.

A second reason is that, traditionally, in applied psychology, the relationship between personality and vocational interests is considered to be a highly relevant topic (Larson et al., 2002; McKay \& Tokar, 2012; Mount et al., 2005; Schermer et al., 2015). Accordingly, if the GFP is indeed a substantive factor in the hierarchical structure of personality, it is also important to know how this factor relates to vocational interests vis à vis other personality constructs (such as the Big Five). As science often aims to reveal the most fundamental and parsimonious explanations for observed phenomena, the GFP may allow a more fundamental explanation for the observed patterns of correlations between specific traits, such as the Big Five with vocational interests. In the sections below, we will elaborate on these reasons for using the GFP in this context. Before doing so, however, we first need to provide a short description of the background and relevance of the GFP.

\section{The General Factor of Personality}

Most currently known personality models, such as the Big Five, the Giant Three, or the HEXACO model, assume multiple, independent personality dimensions. Yet, metaanalyses have clearly confirmed that these dimensions consistently correlate, indicating that they share a relevant proportion of their variance. This shared variance captures the socially desirable ends of the underlying scales (e.g., Musek, 2017; Rushton \& Irwing, 2011; Van der Linden et al., 2010a, 2016). For example, in terms of the Big Five, a general factor emerges that implies that high-scoring individuals seem to be relatively open-minded, hard-working and reliable, sociable, friendly, and emotionally stable. The general factor has not only been identified in the Big Five, but also in virtually every other personality model, such as Eysenck's three-factor model, the six-factor HEXACO, or in the California Personality Inventory (Loehlin, 2012). Moreover, a GFP even emerges when using a personality type approach (Gerlach et al., 2018).

It does not really matter which personality model (e.g., Big Five, HEXACO, PEN) or instrument (NEO, BFI, CPI) one uses to extract a GFP, because the resulting general factors will be highly similar (e.g., Loehlin \& Horn, 2012;
Rushton \& Irwing, 2011; Van der Linden et al., 2016). The only condition is that a sufficiently broad range of personality traits is taken into account so that the GFP truly reflects a mix of different traits. Thus, the principle of the "indifference of the indicator" (Jensen, 1998) also applies to the GFP. As an illustration, the direct correlations between general factors from different personality models/instruments is around $r=0.60$ (e.g., Loehlin \& Horn, 2012; Van der Linden et al., 2011). More sophisticated modeling showed that the associations between GFPs extracted from different comprehensive personality measures reaches unity (Rushton \& Irwing, 2011).

The GFP is not only robust regarding model or instrument, but also regarding statistical method: Different ways of extracting the GFP all lead to nearly identical results (Van der Linden et al., 2017). This makes sense, because the different statistical methods, at the end, capture the shared variance among personality traits. Thus, exploratory factor analytic techniques, such as principal axis factoring, or more complex confirmatory modeling techniques, lead to GFPs that typically correlate in the range of $r=0.90$ to 1.00 . It also does not make a conceptual difference whether one will test hierarchical or bi-factor models. Crede and Harms (2015) stated that “. ...admittedly, one of the superior alternative models, the bi-factor model (BFM), would result in an interpretation that is similar to that arising from the higherorder factor model" (p. 857).

Although the existence of a GFP is now beyond reasonable dispute, there is an ongoing scientific debate regarding its presumed nature. Initially, some scholars considered the GFP to mainly reflect methodological artifacts, such as response tendencies or an inflated sense of self when filling out self-reports (Bäckström et al., 2009; Connelly \& Chang, 2016; Revelle \& Wilt, 2013). Other scholars suggested that the general factor may be a statistical artifact caused by correlations at the facet level (Ashton et al., 2009). If such artifact explanations are valid, then the GFP does not reflect a person's 'true personality', but would merely be a nuisance in personality assessment.

In contrast is the notion that the GFP is substantive and reflects a genuine trait (Figueredo et al., 2004; Musek, 2007; Rushton et al., 2008). The currently leading substantive interpretation is that it reflects general social effectiveness (Dunkel \& Van der Linden, 2014; Loehlin, 2011; Van der Linden et al., 2016). In this view, high-GFP individuals are characterized by having social knowledge and skills that help them obtain their goals.

Several lines of empirical findings fit with the social effectiveness account of the GFP. For example, high-GFP individuals do better on ability tests of social knowledge and skills (Van der Linden et al., 2014), the GFP strongly overlaps with measures of emotional intelligence (Anglim et al., 2019; Van der Linden et al., 2017), and it is related 
to various positive social outcomes such as likability/ popularity and leadership (Van der Linden et al., 2010b; $\mathrm{Wu}$ et al., 2020). The GFP has also been linked to a range of other-rated or objective outcomes in which social effectiveness is assumed to play a role, such as job performance (Pelt et al., 2017). Importantly, several of these previous studies showed that the GFP drives the lion's share of the criterion-related validity of lower-order factors such as the Big Five, or HEXACO (see, for example, the meta-analytic reports of Pelt et al., 2017).

The various arguments and pieces of evidence in the artifact versus substantive views have been extensively addressed in many previous articles and therefore will only be briefly summarized here. One of the key points is whether the GFP is restricted to self-reports, as can be expected from a measurement artifact, or whether it also relates to other-rated or objective outcomes, which would be in line with the substantive account. Above, we already referred to studies that have confirmed that the GFP indeed relates to other-rated and objective outcomes. Moreover, GFPs extracted from self-reports substantially overlap with GFPs extracted from other-ratings of personality (Oltmanns et al., 2018; Rushton et al., 2008). Some studies seemed to suggest that there is no overlap on GFPs from self and other ratings (e.g., Chang et al., 2012). However, in each of these cases, close scrutiny of the paper reveals that debatable controls were used to make the general factor "disappear", and by doing so, the studies may have taken away much (if not all) of the true variance of the GFP (Van der Linden et al., 2021).

Ashton et al. (2009) proposed an alternative model, in which correlations between facets are merely causing the impression of higher-order factors above the six HEXACO dimensions. Subsequently, they showed that no higher-order factors appear when controlling for facet-level correlations. This approach, however, does not explain what may cause the intercorrelations between facets or why theoretical explanations at the facet level should have precedence over explanations assuming higher-order factors (Van der Linden et al., 2016).

Finally, there is evidence showing that removing the socially desirable component of personality items decreases the size of the GFP (Bäckström et al., 2009). The limitation of that approach is that it remains unclear whether one can remove socially desirable content without changing the nature of the items and losing their criterion-related validity (e.g., whether it still predicts job performance). Moreover, even though the GFP is reduced in size with this approach, it does not completely disappear. In fact, the authors that originally tested the effect of social desirability on the GFP recently acknowledged that a relevant (substantive) general factor seems to be present in personality measures (Bäckström et al., 2020).
In conclusion, although the last word in the GFP debate has not been spoken, there is sufficient evidence suggesting that the substantive account is a reasonable hypothesis that needs further testing. Yet, if the GFP indeed would be substantive, then a subsequent question is, why would it be useful to pay attention to such a general factor? One theoretical reason for doing so is that it might partly explain why so many previous meta-analyses with, for example, the Big Five, have found relations to outcomes, such as job performance, self-esteem, psychopathology, and many others (Oltmanns et al., 2018; Oshio et al., 2018; Pelt et al., 2017), in a pattern of $\mathrm{O}+, \mathrm{C}+, \mathrm{E}+, \mathrm{A}+$, and $\mathrm{N}-$. Such a common pattern could be partially and parsimoniously explained by the GFP as the driving force behind the associations found. Another possible advantage of the GFP is that it might be able to unify various theories or models of individual differences. For example, it has been used to integrate the literature on personality and emotional intelligence by arguing that emotional intelligence may exert influence on most of the specific personality dimensions, thereby causing their intercorrelations (Van der Linden et al., 2017). The practical relevance of the GFP includes that it has found to be relevant for personnel selection (Pelt et al., 2017) and that it has clinical relevance because low scores indicate a range of psychological problems (Oltmanns et al., 2018).

\section{The GFP and Vocational Interest}

One imperative reason for examining the link between the GFP and vocational interests is that it provides a novel way of testing the social effectiveness hypothesis. Specifically, it can be expected that people tend to have a preference for activities and occupational areas in which they can excel (Nye et al., 2012; Su, 2012). Someone who has a talent or is skilled in calculations would, on average, be interested in professions or activities in which those skills and talents can be used. In the same line of reasoning, if a person would be socially effective, it can be expected that they prefer occupations in which they can express their social skills that are presumably central to the GFP.

Accordingly, it can be expected that the GFP would be particularly related to vocational areas that more strongly rely on social interactions. Being socially effective may be helpful in almost any job, but various vocational interest models clearly point to some areas in which social effectiveness is more salient and/or important (Su, 2012). One of the most prominent interest models is Holland's RIASEC model, which distinguishes six basic higherorder factors of vocational interests, namely realistic, investigative, artistic, social, enterprising, and conventional interests (Holland, 1997). Particularly, the social and enterprising interests are related to preferences in 
working with people or achieving success by means of social interactions, respectively (Berings et al., 2004; Su, 2012). The other dimensions in the model more strongly refer to working with things (e.g., realistic) or ideas (e.g., investigative). Thus, in the Holland model, it can be expected that the GFP may particularly relate to those dimensions in which social interactions play an important role.

If the GFP would only represent response bias or socially desirable responding, it would not be obvious why it would be particularly related to occupations with stronger social components, unless people who have a tendency to fake higher scores on socially desirable personality traits may also have a tendency to fake more interest in social desirable occupations. In that case, the resulting GFP-interests correlation would still reflect artifact. However, there are no studies suggesting that social or enterprising interests are more socially desirable compared to, for example, artistic or investigative interests. Indeed, studies on occupational prestige suggest that social occupations often are accompanied with lower payment and prestige compared to, for instance, technical jobs (Bose \& Rossi, 1983; Duncan, 1961).

A second reason for including the GFP is to gain more fundamental insight into the relationship between personality and vocational interests. Previous studies and metaanalyses on this topic have, without exception, considered the personality dimensions under study mostly as conceptually independent traits (Larson et al., 2002; Mount et al., 2005). This approach has theoretical and analytical consequences. Theoretically, it implies that one has to develop separate explanations for each specific relationship between a certain personality trait and an interest, whereas there may be more general processes involved that have a broader influence on multiple traits. Thus, the GFP potential may contribute to a deeper understanding of what drives the overlap between traits and interests.

Analytically the "separate trait approach" often leads to researchers adopting regression analyses, in which the shared variance of the personality dimensions has been taken out of the equation (i.e., the regression controls for the overlap). This means that one actually examines the residuals of the personality dimensions (for example those aspects of extraversion or openness that are not shared with other traits) instead of how the traits were initially measured. Yet, from a GFP point of view, the shared variance between traits is relevant, or even crucial, and omitting it would dismiss part of the driving force behind the relationship between personality and vocational interests. In the present research, we will address the topics outlined above in four large datasets, including different measures of personality and vocational interests.

\section{General Scores and Genetic Influences}

When examining the link between the GFP and vocational interests, there are two other topics that we consider imperative to include. The first is the shared variance among vocational interests (a general factor of interests or profile elevation). The second is the possible genetic component of the relationship. Both topics provide useful additional information in order to gain insight into the GFP-vocational interest relationship.

\section{Profile Elevation}

Similar to personality research, a general factor has also been identified in vocational interests, which is often referred to as profile elevation (Gottfredson \& Jones, 1993; Fuller et al., 1999). This reflects a general tendency to score higher on all types of interests. Comparable to research on the GFP, there is an ongoing debate about the nature of profile elevation (Tracy, 2012). Some scholars consider profile elevation a social desirability or response tendency factor, and thus a nuisance in the valid assessment of vocational interests (e.g., Prediger., 1998). Others, however, have hypothesized that profile elevation is substantive and has theoretical and practical implications (Fuller et al., 1999; Hirschi \& Läge, 2007). They argued that it reflects a broad interest in a wide range of activities/occupations and may provide useful information for counselors. Currently, the evidence for both sides is mixed. Profile elevation has been found to relate to career planning and career exploration, suggesting that it is substantive (Fuller et al., 1999; Hirschi \& Läge, 2007). On the other hand, Holtrop et al. (2018) compared self and other ratings and found that, although others could fairly well rate the specific vocational interests of a target, the self-other agreement was much lower for profile elevation, which indicates that it is mainly a within-rater effect as would be expected from an artifact. This latter finding differs from findings in the field of the GFP in which self and other ratings show relatively good agreement (Oltmanns et al., 2018).

As profile elevation is a relevant topic in this area, covered in hundreds of articles, it should not be ignored when conducting research on the GFP and vocational interests. The inclusion of profile elevation can provide a unique piece of information regarding the nature of both factors. If profile elevation as well as the GFP would both reflect social desirability or response tendencies, they can be expected to correlate substantially. Specifically, if someone has a tendency towards socially desirable answers, then there is no reason to believe this would be different 
when responding to interest items. In that case, the correlation can be expected to be similar to the average correlation between GFPs extracted from different personality measures (mean $r \approx 0.50-0.60$; Van der Linden et al., 2011). In contrast, a low correlation between the GFP and profile elevation would argue against a common underlying mechanism and would be more in line with the notion that at least one of them is (or both are) substantive.

\section{Genetic Correlations}

The second logical step of elaboration on the GFP-interests relationship involves testing its genetic component. Examining the heritable component provides additional insight into the etiology of the GFP-vocational interest relationship. By using twin research, it is possible to estimate to what extent phenotypical (observed) relationships are due to genetics, shared environmental influences (e.g., SES, parental style), and unique experiences (e.g., peers) and measurement error. It has already been established that the GFP as well as vocational interests have a substantial heritable component (Figueredo \& Rushton, 2009; Loehlin, 2011; Veselka et al., 2009). Yet, this does not necessarily mean that their correlation has a genetic basis. In principle, their relationship could still be entirely due to environmental influences. On the other hand, there is also the possibility that there are sets of genes that have a broad influence on behavior and that may affect personality, i.e., the GFP, as well as vocational interests. If this is the case, we may speak of pleiotropy (Keller et al., 2010).

Although to our knowledge, there are no previous studies that have directly tested the genetic correlation between the GFP and vocational interests before, there have been studies that tested the genetic correlation between emotional intelligence (EI) and vocational interests. Those are relevant to mention here because of the strong overlap between EI and the GFP (Van der Linden et al., 2017, 2018). Schermer et al. (2015) found that EI was mainly related to occupations that involved working with people (e.g., social services, personal services, education), and those associations were present at the genetic level as well as the unique environmental level. Thus, in as far as the GFP reflects social effectiveness that overlaps with EI, we may expect a similar pattern of relationships with vocational interests. That is, we expect that even at the genetic level, the GFP will particularly relate to interests in occupations with a relatively strong social component. This will be tested in study 3 , in which we examined the sample of same-sex monozygotic and dizygotic twins in the well-known National Merit Study (Loehlin and Nichols, 1976).

\section{Study 1: The GFP and Vocational Interests}

\section{Method}

\section{Samples}

Study 1 included two large datasets in which we tested the basic relations between the GFP, based on the Big Five, and vocational interests. The first dataset $(N=752)$ was from the Professional Worker Career Experience Survey (PWECS: Rosenbloom \& Ash, 2009) collected between 2003 and 2004. The study was designed to test for causes of the underrepresentation of women and minorities in IT. However, it included IT as well as non-IT employees. Besides personality items, the sample included vocational interest items allowing the extraction of Holland's dimensions as well as personal styles reflecting one's broad preference for living, learning, playing, and working (Harmon et al., 1994). $56.7 \%$ of the sample was male and $43.3 \%$ female. The mean age was $38.75(S D=9.75)$, ranging from 22 to 70 .

The second dataset was downloaded from the website Openpsychometric.org, and included vocational interests and the Big Five. The site Openpsychometric.org offers a range of large datasets on various topics that have been used in many previous scientific publications in journals such as the Journal of Research in Personality, Journal of Personality, Personality and Individual Differences, and Psychometrika (see the full list of articles on: https:// openpsychometrics.org/_rawdata/cited/).

After selecting for the age range 18 to 99 , and screening for outliers, a sample of 108,209 participants from 190 different countries was obtained. Most participants (the top $5)$ were from the USA $(n=80,574)$, Malaysia $(n=7741)$, Canada $(n=7256)$, Singapore $(n=5769)$, and Great Britain $(n=5533)$. The average age was $29.35(S D=11.8)$, and $66.4 \%$ was female, $33.9 \%$ male, and $0.7 \%$ other, or provided no information.

\section{Measures}

Dataset 1 In the PWECS, the Big Five were measured with sixty items (Rosenbloom \& Ash, 2009) on a 5-point Likert scale. Reliabilities of the scales were good, ranging from 0.75 , for openness and agreeableness, to 0.88 for neuroticism. Example items are openness, "Poetry has little or no effect on me" (reverse); conscientiousness, "I work hard to accomplish my goals"; extraversion, "I like to be where the action is"; agreeableness, "I generally try to be thoughtful and considerate"; and neuroticism, "I am seldom sad or depressed" (reverse coded). In line with the many previous 
articles in the field, the Big Five dimensions were used to extract the GFP (see the "Results" section).

Vocational interests and personal styles were measured with the Strong Interest Inventory (SII) consisting of 317 items covering a wide range of jobs, activities, and characteristics. The jobs and activities items could be answered on a 5-point Likert scale ranging from strongly dislike to strongly like. The characteristics items also were in a 5-point Likert format ranging from strongly unlike me to strongly like me. The SII was originally developed by Strong (see Donnay, 1997) to find suitable jobs for people who left the military. It was later revised; however, so that it could be applied to the general population (Blackwell \& Case, 2008). From the SII, six General Occupational Themes (GOT) can be derived (see Rosenbloom \& Ash, 2009) representing the six factors in the Holland model, namely realistic, investigative, artistic, social, enterprising, and conventional. Among these factors, the social and enterprising dimensions are the ones with the strongest social components.

In addition, parallel to the six Holland dimensions, the 317 items of the SII allowed extraction of five personal styles that indicate interests in things versus people (work style), preferred learning style (learning style), interest in obtaining a leadership position (leadership), tolerance/preference for risks (risk taking), and interest in working in teams versus being more individualistic (team orientation). The validity of the SII and its derived dimensions of vocational interests and personal styles have been confirmed in a large number of previous studies (see Rosenbloom \& Ash, 2009).

Dataset 2 In this sample, personality was measured with the short Ten-Item Personality Inventory (TIPI), which is a short but reliable Big Five Inventory (Gosling et al., 2003). The items contained target descriptions, and the participant had to indicate, on a 5-point Likert scale, to which extent they apply to them. Examples are conventional, uncreative (reverse coded) for O; dependable, self-disciplined for C; extraverted, enthusiastic for $\mathrm{E}$; sympathetic, warm for A; and anxious, easily upset for N. For the TIPI, the Big Five dimensions were used to extract the GFP (see the "Results" section).

Markers of the six vocational interest dimensions from the Holland model were developed and validated by Liao et al. (2008). The survey consisted of 48 items ( 8 for each dimension) that described several different occupational activities (e.g., interact with students in a classroom setting, analyze financial information). Participants were instructed in the following way: "This inventory contains a list of activities to help you explore your vocational interests. Please indicate how much you would like to do each activity by circling the number that most closely represents how you feel about it".
The response format was a 5-point Likert scale ranging from 1 strongly dislike to 5 strongly like. The general interest factor (see Introduction) in this measure explained $39.88 \%$ of the variance in the six dimensions. The general factor loaded on the six interest dimensions as follows: $0.55,0.35,0.43$, $0.48,0.72$, and 0.60 , for R, I A, S, E, and C, respectively.

\section{Statistical Analysis}

The focus in study 1 was on testing the relationship between the GFP and occupational preferences. However, before doing so, we first had to extract the GFPs from the datasets. Many previous studies have confirmed that a GFP can be consistently found in any Big Five measure (for a metaanalysis, see Van der Linden et al., 2010a, 2010b), and one prevalent method is to extract the first unrotated factor from scale scores by means of principal axis factoring (PAF). The literature also shows that, although different, more sophisticated methods can be used, the characteristics of the GFP often remain highly similar (Loehlin, 2011; Musek, 2007; Van der Linden et al., 2017): GFPs extracted with different statistical methods correlate near unity (e.g., between 0.95 and 1). Accordingly, in the present studies, we report the main analyses with the GFPs extracted via PAF, but in the supplementary material, we also provide the statistical analyses in which the GFP was extracted with alternative methods (i.e., confirmatory factor analysis: CFA). For evaluating the models, we used the guidelines for model fits as reported by $\mathrm{Hu}$ and Bentler (1999).

The GFP-vocational interest relationships were tested by zero-order and partial correlations. In the partial correlations, we controlled for gender. Although, many studies used gender as an almost standard covariate, Spector and Brannick (2011) pointed out that the decisions surrounding the use of control variables are not as straightforward as many assume. Control variables sometimes indeed cause noise and attenuate or inflate true relationships. In that case, using control variables provide better estimates of the tested relationship. On the other hand, sometimes control variables are used incorrectly and take away part of the true overlap between variables of interest. Therefore, they advise to provide adequate reasoning for adopting control variables. Regarding this, one of the reasons for including gender as a control variable was that it is well-established that gender is related to vocational interests. Women, on average, show stronger interest in social occupations (for a meta-analysis see, Su et al., 2009). Whether there are gender differences in the GFP is unclear as the evidence is mixed (Van der Linden et al., 2017).

Nevertheless, the previous findings on gender open a range of possibilities. One is that any GFP-vocational interest relationship may be spurious (see the detailed reasoning in the footnote). The other possibility is that the genders 
differentially relate to social interest due to differences in social effectiveness (i.e., the GFP). Based on the extant literature, we cannot be conclusive regarding the different possibilities. Therefore, for optimal transparency of the findings, we decided that it would be informative presenting the direct associations between the GFP and vocational interests, as well as presenting the associations after controlling for gender.

Beyond directly testing the GFP, it is useful to compare its effects to more common lower-order personality dimensions, i.e., the Big Five. Accordingly, we also tested how the unique variance of the Big Five dimensions (after taking out their shared component, i.e., the GFP) relates to the various vocational interests. The unique variance of each of the Big Five dimensions was obtained by regressing the GFP on each of the separate Big Five dimensions and saving the standardized residuals.

\section{Results}

\section{GFP extraction}

Using PAF to extract the first unrotated factor in the personality measures in dataset 1 (PWECS) revealed that the GFP explained $39 \%$ of the variance in the five dimensions (eigenvalue $[E V]=1.9$ ). Conscientiousness, extraversion, agreeableness, and neuroticism all showed substantial GFPloadings in the expected direction and were $0.57,0.63,0.38$, and -0.64 , respectively. Similar to several previous studies (see Van der Linden et al., 2010a for a meta-analysis), the GFP-loading on openness was low (0.04), suggesting that this latter dimension is the least stable regarding the GFP. The GFP was extracted using the regression method in which a participant's score on the GFP is the sum of the score on each specific personality dimension multiplied by its general factor loading.

The supplementary material (S1) shows the results and models of the CFAs. To summarize, the model with the best fit was the one in which the GFP was directly extracted from the Big Five scales. The correlation between the GFP obtained via that model and the one obtained via PAF, obviously, correlated $r=1.00$. Alternative models in which we extracted the GFP from a hierarchical model, including intermediate higher-order factors showed a reduced fit. Regardless of what CFA model was used to extract the GFP, the correlations with the GFP from the PAF always fell in the range from $r=0.97$ to 1.00 . Models that assumed unrelated Big Five dimensions (no higher-order factor) showed very poor fit.

In dataset 2, the GFP was extracted from the ten-item TIPI. Although the TIPI has been shown to be a valid measure of the Big Five, due to the smaller number of items, by definition, it also includes more error variance.
Nevertheless, the GFP extracted from the TIPI explained $32.56 \%(E V=2.27)$ of the variance in its underlying Big Five dimensions, with loadings of $0.41,0.47,0.34,0.38$, and -0.37 , for, $\mathrm{O}, \mathrm{C}, \mathrm{E}, \mathrm{A}$, and $\mathrm{N}$, respectively. The details of the CFAs for this measure are also reported in the supplementary material (S1). Overall, however, the findings of those analyses reveal the same picture as in dataset 1 . That is, regardless of the specific model used (e.g., direct GFP model, GFP extracted from a hierarchical model, a bi-factor model), the GFPs always correlated in the range of $r=0.95$ to 1.00 with the GFP extracted with the PAF.

\section{The GFP and Vocational Interests}

Table 1 shows the zero-order correlations between the variables in datasets 1 and 2. Despite the differences in samples and measurement of the Big Five and Holland's dimensions, the correlations were remarkably consistent across the two samples. In both, the GFP mainly related to social and enterprising interests. In dataset 1 , social and enterprising were the only two dimensions significantly related to the GFP. Due to the large $N$, looking at significant levels was less meaningful in dataset 2 , but in that sample, social and enterprising also clearly showed the strongest associations with the GFP.

In dataset 1 , the GFP was significantly and positively related to all personal style dimensions, and the dimensions work style, leadership, and team orientation, which all clearly refer to social skills and interests, displayed the highest correlations. The direct correlations between the GFP and profile elevation were also consistent in the two datasets, namely, $r=0.13$ and 0.14 . These correlations suggest that the overwhelming majority of the variance in the two constructs was unique.

As expected (see the "Method" section), there were various relevant correlations with gender. In absolute sense, in both datasets, women scored higher than men on the GFP. Effect sizes were small though (Cohen's $d=0.05$ and 0.08 for datasets 1 and 2, respectively). The difference did not reach significance in the PWECS sample $(p=0.25)$ and was obviously significant in the OpenPsychometrics data, which was mainly due to the large $N$. In line with the literature, gender was also related to vocational interest (see Table 1), with women showing stronger interest in social occupations (for a meta-analysis, see Su et al., 2009).

The partial correlations are presented in Table 2 and allow the readers to directly compare the direct associations with those after controlling for gender. The partial correlations confirmed the initial pattern of results because the GFP only remained particularly related to social and enterprising interests. In dataset 1 , all personal style measures remained related to the GFP, but those involving working with people, 


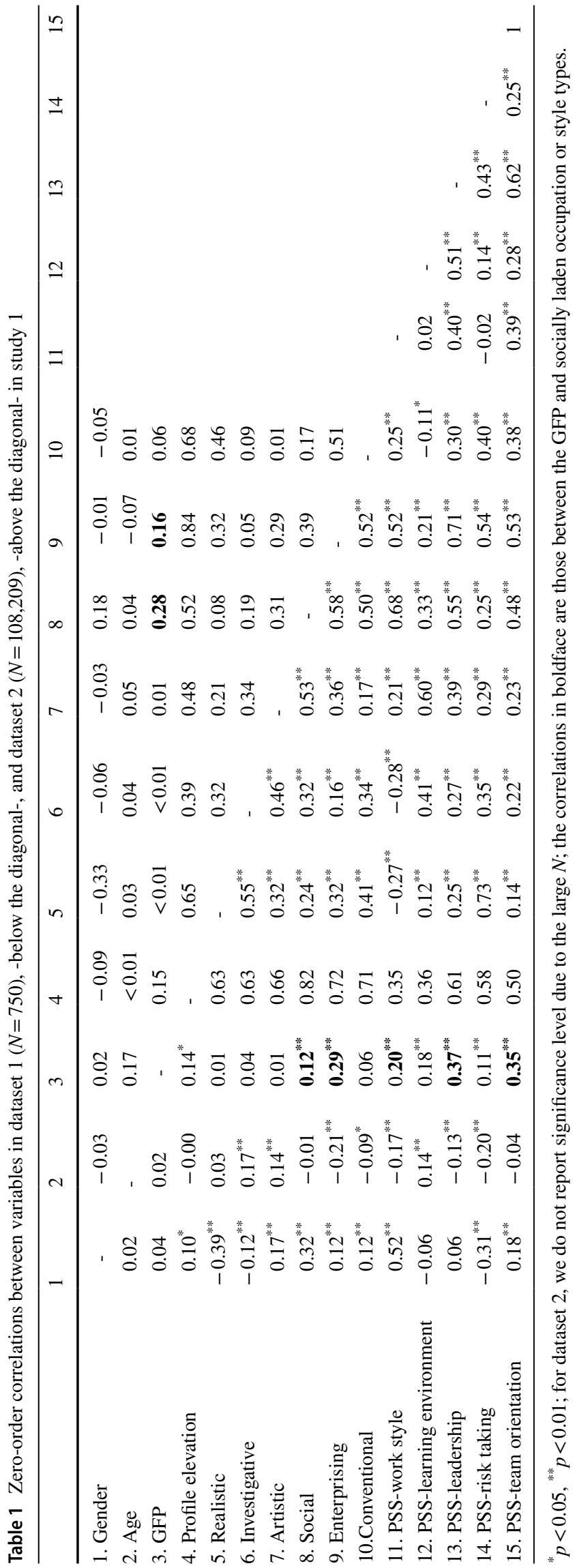

having a team orientation and interest in leadership, were particularly pronounced.

\section{The GFP Versus the Big Five}

In order to compare the GFP to the Big Five, we conducted subsequent analyses in which we first tested how the Big Five directly relate to the vocational interests, and then tested how those correlations change after only considering the unique variance of the Big Five dimensions (i.e., after taking out the GFP). In addition, we examined how much variance in vocational interest is explained by the combined unique variance of all the Big Five dimensions and compared that to the vocational interest variance explained by the GFP. Those results are presented in Tables 3 and 4.

The pictures that emerged in the two datasets, again, converged. First, in line with previous meta-analyses (Larson et al., 2002; Mount et al., 2005), the Big Five showed several direct relations to specific interests. For example, in both datasets, extraversion was relatively strongly correlated with enterprising interests, and agreeableness with social interests. When looking at the unique Big Five variances, however, several of these correlations were relevantly attenuated (Table 3). For example, the correlation between extraversion and social interests went from 0.16 to 0.10 and from 0.23 to 0.11 in datasets 1 and 2, respectively, a reduction of $38 \%$ and $52 \%$, respectively. Similarly, the agreeableness-social interest correlations went from 0.18 to 0.14 and from 0.25 to 0.13 in datasets 1 and 2, respectively.

For four of the six vocational interests from the RIASEC model (R, I, A, and C), the GFP did not show a strong contribution to the level of explained variance whereas the combined unique characteristics of the Big Five explained the most variance (see Table 4). However, for the social and enterprising interests, the GFP explained significant percentages of the variance, whereas the combined unique aspects of the Big Five contributed less explained variance beyond the GFP.

\section{Discussion}

In the two datasets in study 1, viable GFPs could be extracted, explaining relevant proportions of the Big Five variance. We report the results on the GFPs extracted as the first unrotated factor. However, in line with the literature (Van der Linden et al., 2016, 2017), it also was clear that the GFP is robust for specific extraction method because general factors extracted with various CFA models (e.g., hierarchical or bi-factor models) overlapped near unity with the GFP extracted with PAF. The factor loadings were typical in the sense that the GFP seems to reflect socially desirable or effective behavior (Loehlin and Horn, 2012). 
Table 2 Partial correlations (controlling for sex) in the two datasets in study 1 on vocational interests and personal styles with the GFP

\begin{tabular}{lll}
\hline & $\begin{array}{l}\text { Dataset 1 } \\
(N=725)\end{array}$ & $\begin{array}{l}\text { Dataset 2 } \\
(N=108,209)\end{array}$ \\
\hline Vocational interests & & \\
$\quad$ Realistic & 0.05 & $<0.01$ \\
Investigative & 0.05 & 0.01 \\
$\quad$ Artistic & 0.01 & 0.02 \\
Social & $\mathbf{0 . 1 2 ^ { * }}$ & $\mathbf{0 . 2 8}$ \\
Enterprising & $\mathbf{0 . 3 1}$ & $\mathbf{0 . 1 6}$ \\
Conventional & 0.07 & 0.06 \\
$\quad$ Profile elevation & $0.13^{* *}$ & 0.15 \\
Personal style (dataset 1 only) & & \\
Work style & $0.21^{* *}$ & \\
Learning environment & $0.19^{* *}$ & \\
Leadership & $0.41^{* *}$ & \\
Risk taking & $0.16^{* *}$ & \\
Team orientation & $0.34^{* *}$ & \\
\hline
\end{tabular}

For dataset $1,{ }^{*} p<0.05,{ }^{* *} p<0.01$; for dataset 2 , we do not report significance levels due to the large $N$

The results of the two large datasets in study 1 were consistent and in line with main expectations. That is, the GFP mainly related to social and enterprising interests in the Holland model and these associations and conclusions remained, even after controlling for gender. The personal style measures in dataset 1 were all significantly related to the GFP, but those involving working with people, in teams, or leadership clearly showed the strongest associations.

In Holland's model, enterprising reflects a dimension of "getting ahead" through social means (Wolfe et al., 1986). In dataset 1 , this dimension was even more strongly associated with the GFP than the actual social dimension. Similarly, the GFP in that dataset showed the strongest association with the leadership style, compared to the other personal styles. Those findings indicate that, besides a general interest in social occupations, high-GFP individuals may also be more interested in using social interactions (e.g., with customers, subordinates) to gain status or resources.

Overall, the findings of study 1 were in accordance with the notion that the GFP reflects social effectiveness (Van der Linden et al., 2016). If the findings would be merely due to social desirability or response biases_-such as yea-sayingthen one would rather expect the GFP to be either uniformly related to all interests/styles or otherwise, at least be related to those professional interests that are considered high status or socially desirable. This was not the case. Moreover, the GFP and interest profile elevation correlations were in the range of $r=0.13$ to 0.15 , which indicates that these two constructs were largely distinct. A much stronger correlation would be expected if both factors emerge from the same type of bias(es).
Finally, the comparisons with the lower-order dimensions showed that, the unique variances of the Big Five dimensions often still were related to vocational interests. Nevertheless, regarding socially laden occupational interests, the GFP seemed to be responsible for the lion's share of the relationships. For example, the initial correlation of $r=0.23$ between extraversion and social interest was reduced to 0.11 after taking out the GFP. Again, the overall picture that emerged here was in line with the literature stating that the GFP does not imply that more specific personality dimensions become obsolete (Van der Linden et al., 2017). Rather, it implies that there may be a common core in personality measures that is partly responsible for the observable effects.

Study 1 had limitations. One is that it did not include measures of cognitive ability, which may also relate to vocational interests (Pässler et al., 2015) and the GFP (Dunkel, 2013; Dunkel \& Cabeza-de Baca, 2016; Loehlin, 2011). Second, although study 1 used two of the leading models in personality and vocational interests, it would be useful to test whether the findings conceptually replicate using different measures. For example, based on the literature, it can be assumed that general factors extracted from different personality models or measures, largely reflect the same latent construct (Van der Linden et al., 2011). Accordingly, a GFP extracted from a personality measure other than the Big Five would show similar findings with regard to vocational interests. Third, both samples consisted of many people who already had jobs or were active on the labor market. One possible effect of this is that, even though vocational interests have shown to be fairly consistent throughout one's life, the reported vocational interest may have been partially influenced by the type of occupation in which the participants were already employed.

\section{Study 2: Vocational Interests in Project Talent}

Study 2 was conducted as a conceptual replication and addressed the limitations of study 1 . We used data from Project Talent, which is a well-known and large study from the 1960s in which roughly $5 \%$ of the entire US high-school population was sampled (American Institute for Research, Project Talent, 1960). We focused on the data in the last year of high school in which vocational interests may have been more strongly developed and were also the most relevant, because they directly relate to the educational or vocational choices in the subsequent year. Another advantage of having high-school students as participants is that they were not yet strongly exposed to working life (although some students may have had part-time or summer jobs). This largely addressed a possible alternative causal explanation being that the profession one works in influences personality as 


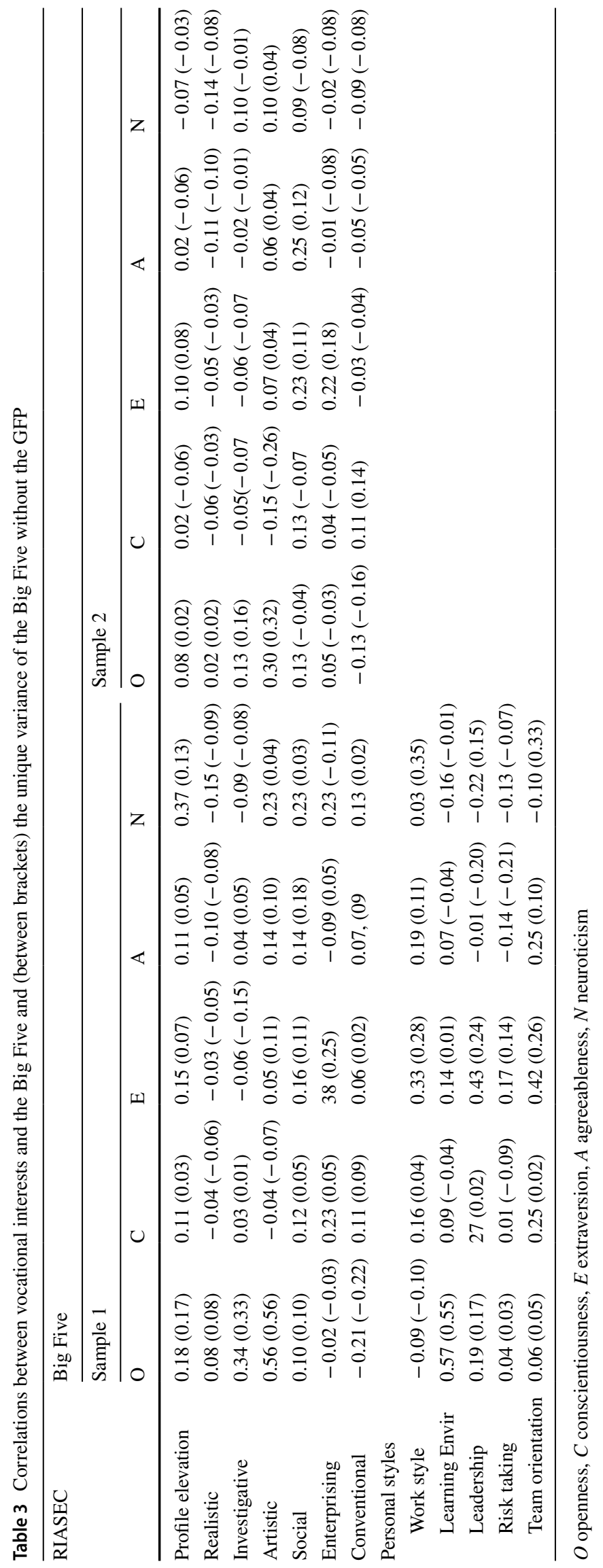


Table 4 Percentages of explained variance $\left(R^{2} \Delta\right)$ in vocational interest by the GFP and the combined unique variances of the Big Five in both samples in study 1

\begin{tabular}{|c|c|c|c|c|c|c|}
\hline \multicolumn{7}{|l|}{ Dataset 1} \\
\hline & \multicolumn{3}{|l|}{ Step 1: GFP } & \multicolumn{3}{|c|}{ Step 2: combined unique Big Five } \\
\hline & $R^{2} \Delta$ & $F(1,556)$ & $p$ & $R^{2} \Delta$ & $F(4,552)$ & $p$ \\
\hline Realistic & $<0.01$ & 0.03 & 0.861 & 0.03 & 4.57 & 0.001 \\
\hline Investigative & $<0.01$ & 0.72 & 0.397 & 0.14 & 23.04 & $<0.001$ \\
\hline Artistic & $<0.01$ & 0.10 & 0.750 & 0.33 & 66.94 & $<0.001$ \\
\hline Social & 0.02 & 8.29 & 0.004 & 0.07 & 10.18 & $<0.001$ \\
\hline Enterprising & 0.08 & 51.24 & $<0.001$ & 0.08 & 13.88 & $<0.001$ \\
\hline Conventional & $<0.01$ & 2.28 & 0.13 & 0.07 & 9.77 & $<0.001$ \\
\hline \multicolumn{7}{|l|}{ Dataset 2} \\
\hline & \multicolumn{3}{|l|}{ Step 1: GFP } & \multicolumn{3}{|c|}{ Step 2: combined unique Big Five } \\
\hline & $R^{2} \Delta$ & $F(1,556)$ & $p$ & $R^{2} \Delta$ & $F(4,552)$ & $p$ \\
\hline Realistic & $<0.01$ & 308.71 & $<0.001$ & 0.03 & 731.64 & $<0.001$ \\
\hline Investigative & $<0.01$ & 5.04 & 0.03 & 0.03 & 912.55 & $<0.001$ \\
\hline Artistic & $<0.01$ & 475.98 & $<0.001$ & 0.13 & 3893.78 & $<0.001$ \\
\hline Social & 0.08 & 9031.34 & $<0.001$ & 0.07 & 1119.57 & $<0.001$ \\
\hline Enterprising & 0.02 & $1,535.30$ & $<0.001$ & 0.04 & 996.17 & $<0.001$ \\
\hline Conventional & $<0.01$ & 0.49 & 0.49 & 0.04 & 1061.05 & $<0.001$ \\
\hline
\end{tabular}

well as vocational interest (i.e., reversed causation). Lastly, an additional asset of the Project Talent data was that it included cognitive tests, which allowed for the extraction of a general cognitive ability factor. Cognitive ability is known to relate to vocational interests, for example, higher cognitive ability has been shown to relate to more complex (e.g., computer programming) or investigative jobs (Pässler et al., 2015).

In addition, several studies suggest that there may be a positive correlation between cognitive ability and the GFP (e.g., Dunkel et al., 2014). Similar to our lines of reasoning on gender as a control variable, we consider cognitive ability a relevant control variable to examine. For example, based on the literature, there is the possibility that cognitive ability may be "the hidden variable" that relates to the GFP as well as vocational interest. In that case, the GFP-vocational interest association would be spurious and disappear or otherwise substantially diminished after controlling for cognitive ability. Alternatively, cognitive ability might also be a statistical suppressor of the true GFP-interests associations and controlling for it would then increase the associations. Another option is that despite their possible intercorrelation, the GFP and cognitive ability may mostly influence unique parts of the variance in vocational interests. If that is so, controlling for cognitive ability would not have strong effect on the GFP-interest associations. Again, the current literature is not conclusive about these possibilities, and for reasons of transparency, we consider it informative to report the direct associations between the GFP and vocational interests as well as those after controlling for cognitive ability. Overall, the main aim of study 2 was to conceptually replicate the relationship between the GFP and interests in jobs and activities (in the "Method" section, the specific interest dimensions are explained) with a different set of personality and interests measures.

\section{Method}

\section{Sample}

In study 2, the sample was drawn from the Project Talent (https://www.icpsr.umich.edu/web/NACDA/studies/33341), which was a large national-wide study in the USA that in the 1960s started surveying high school students from 1353 schools across the country. A full description of the procedures and test constructions is provided by Flanagan (1962). For the reasons provided in the "Introduction" section of study 2, we used the sample from the last year of high school. In this sample $(N=81,130)$, the mean age of the participants was 17.25 years $(S D=1.78)$. $48.9 \%$ were male and $51.1 \%$ female.

\section{Measures}

Personality Personality was measured with the Project Talent Personality Inventory (PTPI) that included 150 items and 13 scales, although, only 108 items that made up ten scales were coded in the original project. The items used a Likert format to ask to what extent the item reflects the person. Answering categories ranged from 1 not very well to 5 extremely well. The validity of the ten scales has relatively recently been confirmed by Pozzebon et al. (2013). 
The PTPI contained the following scales: (1) Vigor (VI) reflects the level of physical activity (e.g., I play games for hours without getting tired), (2) calmness (CA) measures the ability to remain stable in emotional situations (e.g., I rarely lose my temper), (3) mature personality (MA) refers to the tendency to take responsibility and finish projects (e.g., I work fast and get a lot done, people say they can count on me), (4) impulsivity (IM) measures the tendency to do things without regard of their consequences (e.g., I usually act on the first plan that comes to mind), (5) self-confidence (SC) assesses one's believe in oneself or self-worth (e.g., I'm equal to any occasion), (6) culture (CU) reflects the level of appreciation of aesthetic and refined taste (e.g., I enjoy works of art), (7) sociability (SO) comprise enjoyment of interacting with people and being optimistic (e.g., I take a big part in social activities, I am good natured most of the time), (8) leadership (LE) entails the motivation to take charge (e.g., I like to make decisions), (9) social sensitivity (SE) relates to empathy (e.g., I don't like to see someone's feelings hurt), and (10) tidiness (TI) reflects the motivation and/or action to keep the environment neat and tidy (e.g., I do my homework as neatly as possible). All scales were coded such that higher scores reflected more favorable outcomes (e.g., higher scores on the scale impulsivity implied less impulsivity).

Vocational Interests Two hundred and four items in Project Talent assessed the level of interest in specific jobs and activities. According to the original researchers of Project Talent, the items could be categorized in 17 broad interest scales, namely (1) physical science, engineering/mathematics, (2) biological science/medicine, (3) public service (e.g., major, committee member), (4) literary-linguistic, (5) social service, (6) artistic, (7) musical, (8) sports, (9) hunting and fishing, (10) business and management, (11) sales, (12) computation, (13) office work, (14) mechanical technical, (15) skilled trades, (16) farming, and (17) labor. Particularly scales $3,5,10$, and 11 can be considered to involve social aspects and social interaction, which may therefore, relate to the GFP. Su (2012) described how the items form hierarchical clusters with the general distinction of interests in things versus interest in people being among the highestorder factors.

General Cognitive Ability Participants in Project Talent were administered various tests that assess a wide range of cognitive abilities and scholastic aptitudes, such as abstract reasoning, mathematics, reading comprehension, and vocabulary. The cognitive tests in the Project Talent have been validated and used in many previous, including the extraction of the general factor of intelligence, or $g$ factor (see $\mathrm{Su}$, 2012 for a review). In total, 16 tests were used in the factor analysis to extract a general factor of cognitive ability. There was a clear general factor in the tests comprising $56.89 \%$ of the total variance ( $54.68 \%$ shared variance) and a mean loading of 0.73 ranging from 0.55 (for vocabulary) to 0.86 (for reading comprehension).

\section{Results}

\section{GFP Extraction}

The existence of the GFP in Project Talent has already been confirmed by the study of Dunkel et al. (2014), who tested the relationship between personality and general cognitive ability. In the present study, we used the same extraction method, namely the first unrotated factor obtained with principal axis factoring. The GFP in this dataset explained no less than $61.38 \%$ (eigenvalue $[E V]=6.14$ ) of the variance in the specific scales. The general factor loaded on each of the scales in the expected direction (i.e., towards social desirability/effectiveness). The mean loading was 0.75 . The specific factor loadings were $0.77,0.79,0.78,0.56,0.69,0.83$, $0.75,0.77,0.83$, and 0.76 for, VI, CA, MA, IM, SC, CU, SO, $\mathrm{LE}, \mathrm{SE}$, and Ti, respectively.

We went beyond Dunkel et al. (2014) by also testing the viability of the GFP in Project Talent using CFA. The details of those analyses are reported in the supplementary material (S1). As a summary, the direct model, in which the GFP loaded on each of the scales, showed an acceptable fit when looking at the CFI and TLI indices (0.93 and 0.91, respectively), but the RMSEA was suboptimal (0.11). Further examination showed that the unique variances of several specific personality scales correlated beyond the general factor. Accordingly, when allowing six correlations between the unique scale variances, the fit improved $(\mathrm{CFI}=0.97$, $\mathrm{TLI}=0.95$, RMSEA $=0.08$ ). Note that allowing those additional correlations had an effect on the fit, they hardly had an effect on the nature of the GFP and its factor loadings (still ranging from 0.55 to $0.84, M_{\text {Loading }}=0.75$ ). More importantly, the latent GFP from the CFA correlated $r=0.99$ with the GFP extracted by means of PAF as described by Dunkel et al. (2014). Alternative models that did not include a general personality factor showed worse fit (see S1).

\section{GFP and Vocational Interests}

Table 5 shows the zero-order correlations between the study's variables. Due to the very large sample size, we do not report significance levels as they are not informative and mainly effect sizes are relevant. The correlations in Table 5 reveal that the GFP was positively associated with the broad interest factor "Working with People", whereas the correlation with the factor "Interests in Things" was rather low.

With regard to the 17 more specific interest factors, and in line with expectations, the GFP showed correlations of 
$r \geq 0.15$ with the clearly social occupational areas of business and management, public services, and social service. In the context of this study, the GFP's higher correlations with biological/medicine, linguistic, musical, and artistic occupations may initially seem less obvious. Yet, in previous research, those latter four occupational categories have been shown to be subsumed under the broader category of working with people (i.e., show higher loadings on the "People factor" than on the "Things factor", e.g., Su, 2012).

Similar to study 1 , there were relevant relations between gender and vocational interests. Noteworthy is the rather strong negative correlation $(r=-0.75)$ between gender and the broad interest factor of "Interest in Things". Females, on average, scored lower on this factor (Su et al., 2009). General cognitive ability showed several associations with vocational interests too. Most of these were positive, the exception being Office work. The two strongest correlations were with hard sciences and engineering, and with life sciences. However, cognitive ability was also positively associated with interests, such as linguistic, artistic, and sport activities.

The partial correlations are reported in Table 6 and show that even after controlling for gender and cognitive ability, the pattern of results remained largely the same. Thus, the findings regarding the link between the GFP and social interests were not merely "a by-product" of gender or cognitive ability.

\section{The GFP Versus the Specific Personality Scales}

As in study 1, we included a test showing the relative contribution of the general factor versus the unique variances of the ten specific personality scales of the PTPI. In doing so, for clarity, we restricted the analyses to the two broad interest categories, things and people. First, we calculated the correlations of each PTPI scale with those categories. Table 7 shows that each of the scales was positively related to interest in working with people (low impulsivity showed the weakest correlation and culture the strongest correlation). However, when only considering the unique variance of the scales-after having taken out the GFP-it is clear that almost all of these correlations became either very small or even reversed sign and became negatively related to interest in working with people. The only exception was culture, which went from $r=0.31$ to 0.18 . A regression with interest in people as the dependent variable, the GFP as a predictor in the first step, and the unique variances of the ten specific scales in step 2 further confirmed the influence of the GFP. Specifically, in the first step, the GFP as a positive predictor explained $6.1 \%$ of the variance in people interest. The 10 unique variances in step 2 became a negative predictor of people interest and explained a smaller proportion of the variance, $5.4 \%$ (see Table 8 ).

\section{Discussion}

In the large sample of Project Talent, study 2 showed conceptual replication by using entirely different personality and vocational interest measures compared to study 1 . Again, the GFP was clearly positively related to a preference for working with people and was not relevantly related to a preference for working with things. Similar to study 1, the results were robust after controlling for gender, and the findings also remained stable after controlling for general cognitive ability.

Regarding the specific vocational interest dimensions, the strongest relationships with the GFP were among those that can reasonably be expected to have more social components, such as public and social services, and business and management (Rosenbloom \& Ash, 2004). The GFP also showed relevant associations with several interest dimensions that would seem less obvious from the social effectiveness perspective, such as literary-linguistic activities and occupations. Su (2012), however, showed that in the Project Talent sample, library science is substantially related to interest in working with people. Thus, in this respect, the correlations between those interests and the GFP fit with the general notion that the GFP particularly relates to jobs with a strong "people" component.

In study 2, it was also replicated that the GFP and a general factor in vocational interests showed a correlation that is not in line with the bias or artifact interpretation. The correlation was $r=0.13$, whereas a much more substantial correlation of $r \approx 0.50$ may be expected if both would have reflected similar response biases or general artifacts.

The comparisons between the relative impact of the shared variance of the personality scales, i.e., the GFP, versus their unique variance also led to as similar picture as in study 1 . When it came to interest in working with people, the GFP explained most of the variance. Beyond that, the total unique variances of the specific scales added a smaller, but still relevant part of the variance in people interest. However, the unique variances of the scales were mainly negative predictors of interest in working with people. Those set findings iterate that a large component of the relations between personality scales and interest in social occupations may be due to the general factor.

\section{Study 3: Testing the Genetic Correlations}

After the findings from studies 1 and 2, a subsequent logical step was to examine the extent to which phenotypical associations between the GFP and vocational interests are at the genetic level. In the introduction, we mentioned that the heritability of the GFP has already been confirmed in several studies that used twin data (Loehlin, 2011; Figueredo \& 


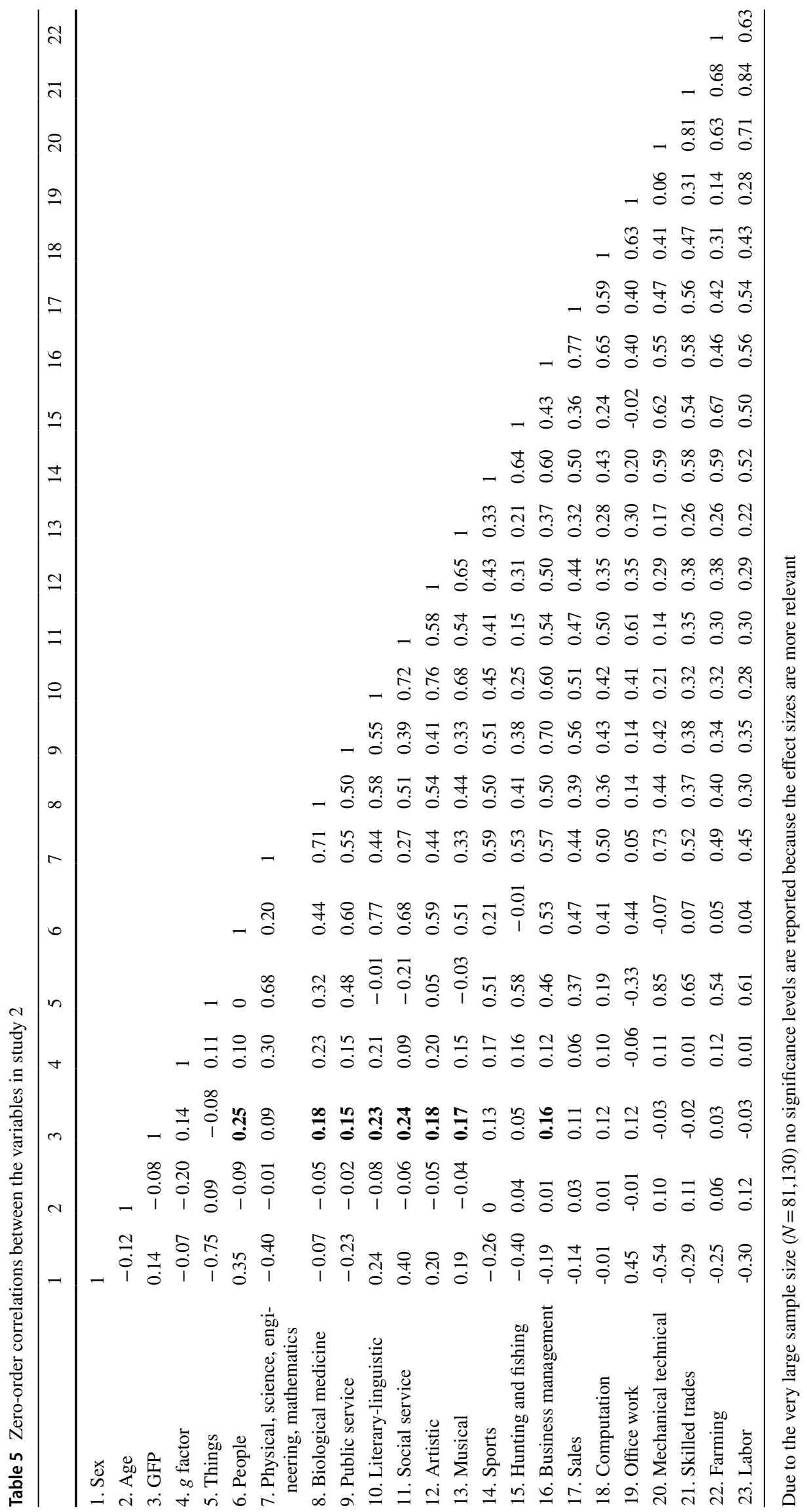


Table 6 Partial correlations (controlling for sex and general cognitive ability) between interests and the GFP $(N=78,436)$

\begin{tabular}{lr}
\hline Interests & \\
\hline Things (factor) & 0.04 \\
People (factor) & 0.20 \\
Physical science, engineering, mathematics & 0.09 \\
Biological Science, medicine & 0.14 \\
Public Service & $\mathbf{0 . 1 5}$ \\
Literary-Linguistic & $\mathbf{0 . 1 5}$ \\
Social Service & $\mathbf{0 . 1 7}$ \\
Artistic & 0.09 \\
Musical & 0.10 \\
Sports & 0.13 \\
Hunting and Fishing & 0.06 \\
Business and Management & $\mathbf{0 . 1 6}$ \\
Sales & 0.09 \\
Computation & 0.08 \\
Office Work & 0.03 \\
Mechanical-Technical & -0.01 \\
Skilled trades & -0.04 \\
Farming & 0.00 \\
Labor & -0.05 \\
\hline
\end{tabular}

Table 7 Correlations between the PTPI dimensions and interests, and the unique variances (between brackets) of the PTPI dimensions and interests

\begin{tabular}{lll}
\hline & Things & People \\
\hline Socioability & $-0.08(-0.03)$ & $0.17(-0.03)$ \\
Social sensitivity & $-0.17(-0.18)$ & $0.26(0.09)$ \\
Impulsiveness & $0.02(0.07)$ & $0.06(-0.09)$ \\
Vigor & $0.08(0.21)$ & $0.12(-0.12)$ \\
Calmness & $-0.02(0.07)$ & $0.16(-0.06)$ \\
Tidiness & $-0.16(-0.16)$ & $0.19(0.00)$ \\
Culture & $-0.19(0.23)$ & $0.31(0.19)$ \\
Leadership & $0.02(0.12)$ & $0.20(0.00)$ \\
Self-confidence & $0.01(0.09)$ & $0.12(-0.07)$ \\
Mature personality & $-0.03(0.06)$ & $0.20(0.02)$ \\
\hline
\end{tabular}

Table 8 Percentages of explained variance $\left(R^{2} \Delta\right)$ in Interest in Things and people, by the GFP and the combined (10) unique variances of the PTPI dimensions

\begin{tabular}{|c|c|c|c|c|}
\hline & \multicolumn{2}{|c|}{ Step 1: GFP } & \multicolumn{2}{|c|}{$\begin{array}{l}\text { Step2: combined } \\
\text { unique PTPI dimen- } \\
\text { sions }\end{array}$} \\
\hline & $R^{2} \Delta$ & $F(1,78,438)$ & $R^{2} \Delta$ & $F(9,78,429)$ \\
\hline Things & $<0.01$ & 503.06 & 0.13 & 1213.37 \\
\hline People & 0.06 & 5121.88 & 0.05 & 536.95 \\
\hline
\end{tabular}

PTPI Project Talent Personality Inventory; because of the huge $\mathrm{Ns}$, no significance levels are provided
Rushton, 2009; Van der Linden et al., 2018; Veselka et al., 2009). An initial study of Power and Pluess (2015) that used genome-wide data, casted some doubts on whether the correlations between the Big Five are also revealed at the genetic level. This is relevant because if there would be no genetic Big Five intercorrelations then that would make it difficult to uphold that there is a genetic GFP. The study of Power and Pluess, however, was based on a relatively small sample for genome-wide analyses. Moreover, many of their estimates did not converge and they could also not confirm the basic heritabilities of several of the Big Five dimensions. In contrast, a more recent genome-wide study of Lo et al. (2017), using a much larger dataset, did confirm the Big Five intercorrelations at the genetic level. In fact, the (absolute) genetic correlations in Lo et al.'s study ranged from I0.11। to 10.40 , with a mean intercorrelation of $r=0.232$, which was remarkably similar to the meta-analytic phenotypical Big Five intercorrelations reported by Van der Linden et al., (2010a, 2010b), which had a mean observed (uncorrected) Big Five intercorrelation of $r=0.225$.

The reason that the present genetic study is useful is that phenotypical correlations can only show that a relationship exists, but they do not provide information about which factors contribute to the correlations. Behavioral genetic analyses with twin data, however, allow a distinction between genetic and environmental factors contributing to associations (Plomin et al., 2008). Such analyses are based on the fact that monozygotic twins share approximately $100 \%$ of their genetic variance, whereas dizygotic twins share, on average, $50 \%$ of their genes. Behavior genetics assumes that monozygotic twins, reared together, do not share more etiological environmental events than dizygotic twins, reared together (Kendler et al., 1993). Therefore, differences in the extent to which monozygotic and dizygotic twins resemble each other are attributed to the effects of genes (i.e., heritability). With behavioral genetic analyses, a phenotypical correlation can be decomposed into additive genetic effects (A), non-additive genetic effects (D), shared environment (C), and non-shared environment (E). The difference between additive and non-additive genetic effects is that in the former multiple genes are assumed to independently contribute to a trait (or correlation between traits). Non-additive genetic effects, on the other hand, imply dominance and/or polygenetic effects (e.g., interactions between genes).

With regard to vocational interests, it is informative to distinguish between environmental and genetic influences on the relationship with personality. If there is a relevant heritable component then this would indicate that genes that influence individual differences in personality, i.e., the GFP, are also involved in individual differences in vocational interests. 


\section{Method}

\section{Sample}

Participants in study 3 were the 768 adolescent twin pairs (1536 individuals) in the National Merit Twin Study. A full description of the procedures and tests are given by Loehlin and Nichols (1976). The twins were identified among the high school students who took the national merit scholarship qualifying test (NMSQT) in the USA in 1962. The monozygotic $(N=509)$ and dizygotic $(N=330)$ pairs were selected out of the roughly 60,000 high school juniors who completed the NMSQT. Using a large 1082-item questionnaire, the study assessed a wide range of variables, including personality and vocational interests, which were the main focus of the present research. The participants were in the eleventh grade at the time of testing. All twin pairs were of the same sex, with $58.2 \%$ being female and $41.8 \%$ male.

\section{Measures}

Personality In the National Merit Twin Study, personality was measured with the 480-item California Psychological Inventory (CPI). The CPI was constructed to assess variation in normal personality (e.g., compared to the Minnesota Multiphasic Personality Inventory, which was developed around the same time, but focused on maladjustment or clinical disorders) and has been validated and used in numerous previous studies. Besides three validation scales, the CPI contains 13 personality subscales assessing a wide range of traits (see Loehlin and Nichols (1976) or Loehlin (2011) for a complete description of the traits).

Vocational Interests Participants filled out the 160 items of Hollands's (1997) Vocational Preference Inventory. The items describe a range of occupational areas and participants had to indicate whether or not they liked the occupations, by answering yes or no. Examples are bookkeeper, musician, army general, and biologist. The scale allows extracting the six RIASEC dimensions similar to those used in study 1 . Twins were randomly labeled as twin 1 or twin 2 . Extraction of the general factor of vocational interests, i.e., profile elevation, showed that this factor explained $33.7 \%$ of the vocational interest variance in twin 1 and $35.7 \%$ of the variance of vocational interests in twin 2 . For twin 1 , factor loadings were $0.38,0.07,0.38,0.63,0.80$, and 0.30 for $\mathrm{R}$, I, A, S, E, and C, respectively. For twins 2, factor loadings were $0.36,0.29,0.50,0.54,0.64$, and 0.47 , for R, I, A, S, E, and $\mathrm{C}$, respectively.

Estimate of General Cognitive Ability The dataset also contains the participants' total score on the NMSQT, which is the combined score of the performance on the five subtests that assess subfields of academic competence (e.g., reading, mathematics). Although the NMSQT was designed to measure scholastic aptitude instead of abstract cognitive skills, it has often been used as an index of general cognitive ability (e.g., Loehlin, 2011). In general, NMSQT scores have been found to show high correlations of around $r=0.80$ with actual IQ scores.

\section{Results}

\section{GFP extraction}

The general factor in the CPI of the National Merit Dataset has already been extensively shown in other studies. Therefore, it would not be useful to present the same analyses again here. Rushton and Irwing (2011) used CFA/SEM to show that in the specific CPI scales in this dataset, six intermediate higher-order factors can be identified, which are subsumed by the two higher-order factors stability and plasticity (see also study 1). The GFP was the highest-order factor loading on stability and plasticity. The model (see Fig. 3 on p. 562, of Rushton \& Irwing, 2011) showed a good fit according to a range of indices. In a later study, Loehlin also extracted the GFP from the same dataset by means of taking the first unrotated factor from principal axis factoring. For reasons of comparison, he extracted GFPs from the CPI scales, from CPI facets, and also directly from the items, only to find that the general factors with the different methods correlated in the range $r=0.92$ to 0.99 . The above pattern of findings confirms that the GFP is robust with respect to extraction method. Accordingly, in the present study, we used the same method as Loehlin (2011) to extract the GFP as the first unrotated factor using PAF. The general factor explained around $34 \%$ of the variance in the underlying subscales. The GFP factor loadings on the scales were in accordance with expectations and ranged from 0.18 (flexibility) to 0.85 (tolerance). See also, Loehlin (2011) and Dunkel et al. (2014) for further information on the GFP and its specific factor loadings in this sample. Each participants' score on the GFP is calculated with the regression method which is the sum of products from their standardized score on each specific CPI scale and its corresponding factor loading.

\section{Personality and Vocational Interests}

The zero-order correlations between the study's variables separately for twins 1 and 2 (the labeling of participants as either twin 1 or twin 2 was random) are displayed in Table 9. The table shows that, although the correlations between the personality and interests were modest overall, the GFP was only significantly correlated with social and investigative interests. Different from the previous two studies was that, 
for twin 1 as well as twin 2, the GFP did not show a significant correlation with enterprising interests.

In this dataset, there were also significant correlations again between gender and cognitive ability, on the one hand, and vocational interests, on the other hand (see Table 9). Based on a similar line of reasoning as in studies 1 and 2, we, therefore, considered it informative to also report the findings after controlling for these two variables. The partial correlations are reported in Table 10 and show that inclusion of the control variables did not change the pattern of findings or conclusions, because investigative and social were still the only two vocational interests that significantly related to the GFP.

As a next step, we estimated the heritability of the GFP and the vocational interests based on the phenotypical resemblance between monozygotic (MZ) and dizygotic (DZ) twins (see Table 11). Because the MZ correlations were not $>2$ times the value of the DZ correlations (see Table 11), we tested the ACE model instead of the ADE model. For all relevant variables, using Cholesky decomposition, we estimated the additive genetic variance (A), the level of variance attributed to the shared environment (C), and the variance component that includes unique environmental variance as well as measurement error (E) (ACE vs saturated: $\chi^{2}(15)=12.17, p=0.76$ ). For each of the variables tested, it was clear that there was no variance attributed to the shared environment (e.g., parenting style, SES). Accordingly, running AE models confirmed that the $\mathrm{C}$ component could be dropped without significant changes in the model fits (AE vs ACE: $\chi^{2}(3)=3.19$, $p=0.36$ ).

In general, from Table 11, it can be derived that, as reported in previous studies, the GFP showed a substantial heritable component of $60 \%$. The heritability of the vocational interest dimensions ranged from $22 \%$ for realistic and conventional to $39 \%$ for social interests.
Table 10 Partial correlations (controlling for sex and general cognitive ability) between vocational interests and the GFP, separately for twin 1 and twin 2

\begin{tabular}{llc}
\hline & Twin 1 & Twin 2 \\
\hline Realistic & -0.03 & 0.03 \\
Investigative & $0.17^{* *}$ & $0.16^{* *}$ \\
Artistic & 0.01 & 0.05 \\
Social & $0.19^{* *}$ & $0.11^{* *}$ \\
Enterprising & 0.05 & 0.07 \\
Conventional & 0.03 & -0.01 \\
Profile elevation & $0.13^{*}$ & 0.07 \\
\hline
\end{tabular}

${ }^{*} p=0.05 ;{ }^{* *} p<0.01$

As social and investigative interests were the only two dimensions that showed significant phenotypical correlations, we tested their genetic correlations with the GFP. The genetic correlation between the GFP and social interest was $r=0.31$ (confidence interval $[\mathrm{CI}]=0.19 ; 0.42$ ) and significant at $p<0.05$. The correlation between the unique environmental components was low $r=-0.01(\mathrm{CI}=-0.09$; $0.08)$ and non-significant. The genetic correlation between the GFP and investigative interests was $r=0.37(\mathrm{CI}=0.23$; $0.50)$ and also reached significance. The unique environmental correlation was low $r=0.09(\mathrm{CI}=-0.01 ; 0.19)$ and not significant.

\section{Discussion}

Using the National Merit sample, we replicated the finding from study 1 and study 2 that the GFP is related to vocational interests with a social component. Study 3 complemented the previous two studies by showing that the GFP and social interest were also significantly related at the genetic level, thereby providing insight into the etiology of the relationship.

Table 9 Zero-order correlations between the variables, separately for twin 1 (above the diagonal) and twin 2 (below the diagonal)

\begin{tabular}{lllllllllll}
\hline & 1 & 2 & 3 & 4 & 5 & 6 & 7 & 8 & 9 \\
\hline 1. Sex & - & $-0.13^{*}$ & 0.02 & $-0.29^{* *}$ & -0.07 & $0.22^{* *}$ & $0.40^{* *}$ & $-0.13^{*}$ & $-0.10^{*}$ & $0.10^{*}$ \\
2. Cognitive ability & $-0.15^{* *}$ & - & $0.33^{* *}$ & $-0.11^{* *}$ & $0.13^{* *}$ & $0.10^{* *}$ & -0.04 & -0.03 & $-0.10^{*}$ & -0.07 \\
3. GFP & -0.01 & $0.36^{* *}$ & - & -0.03 & $0.19^{* *}$ & 0.09 & $0.10^{* *}$ & 0.04 & -0.05 & 0.05 \\
4. Realistic & $-0.23^{* *}$ & 0.01 & -0.04 & - & $0.29^{* *}$ & 0.06 & 0.04 & $0.26^{* *}$ & $0.28^{* *}$ & $0.45^{* *}$ \\
5. Investigative & -0.09 & $0.16^{* *}$ & $0.22^{* *}$ & $0.27^{* *}$ & - & $0.22^{* *}$ & $0.12^{*}$ & 0.09 & 0.05 & $0.35^{* *}$ \\
6. Artistic & $0.18^{* *}$ & $0.19^{* *}$ & 0.09 & 0.04 & $0.15^{* *}$ & - & $0.39^{* *}$ & $0.24^{* *}$ & 0.05 & $0.57^{* *}$ \\
7. Social & $0.33^{* *}$ & -0.07 & $0.16^{* *}$ & 0.00 & $0.11^{*}$ & $0.30^{* *}$ & - & $0.30^{* *}$ & $0.16^{* *}$ & $0.62^{* *}$ \\
8. Enterprising & $-0.16^{* *}$ & 0.01 & 0.04 & $0.26^{* *}$ & 0.05 & $0.26^{* *}$ & $0.29^{* *}$ & - & $0.47^{* *}$ & $0.79^{* *}$ \\
9. Conventional & $-0.10^{*}$ & -0.04 & 0.01 & $0.31^{* *}$ & 0.02 & 0.01 & $0.18^{* *}$ & $0.47^{* *}$ & - \\
10. Profile elevation & -0.07 & 0.01 & $0.13^{*}$ & $0.44^{* *}$ & 0.08 & $0.35^{* *}$ & $0.44^{* *}$ & $0.93^{* *}$ & $0.72^{* *}$ & $-0.67^{* *}$ \\
\hline
\end{tabular}

${ }^{*} p<0.05 ;{ }^{* *} p<0.01$ 
Table 11 Correlations (for $\mathrm{MZ}$ and DZ) and proportion of phenotypic variance due to additive genetic (A), shared environmental (C), and unique environmental and measurement error $(\mathrm{E})$ variance

\begin{tabular}{llllll}
\hline & MZ correlation & DZ correlation & $\mathrm{A}$ & $\mathrm{C}$ & $\mathrm{E}$ \\
\hline GFP & 0.58 & 0.38 & $0.60(0.54-0.65)$ & 0 & $0.40(0.35-0.46)$ \\
Realistic & 0.30 & 0.28 & $0.22(0.12-0.31)$ & 0 & $0.78(0.68-0.88)$ \\
Investigative & 0.35 & 0.20 & $0.36(0.27-0.44)$ & 0 & $0.64(0.56-0.73)$ \\
Artistic & 0.33 & 0.28 & $0.33(0.24-0.41)$ & 0 & $0.67(0.59-0.76)$ \\
Social & 0.47 & 0.26 & $0.39(0.32-0.46)$ & 0 & $0.61(0.54-0.68)$ \\
Enterprising & 0.33 & 0.14 & $0.30(0.21-0.37)$ & 0 & $0.70(0.62-0.79)$ \\
Conventional & 0.24 & 0.12 & $0.22(0.12-0.32)$ & 0 & $0.78(0.68-0.88)$ \\
Profile elevation & 0.20 & 0.38 & $0.27(0.06-0.44)$ & 0 & $0.73(0.55-0.95)$ \\
\hline
\end{tabular}

Confidence intervals (CI) between brackets (all variance levels in columns A and E were significance)
Two findings in study 3 were not entirely in line with studies 1 and 2 . The most salient one is the non-significant relation between the GFP and enterprising interests. The other difference was the significant GFP-investigative interest link. Although, we cannot provide conclusive answers to what may have caused those differences, one plausible explanation is the nature of the sample. In contrast to the previous samples in studies 1 and 2, the National Merit sample consists only of students who scored very high on the initial scholastic aptitude tests (Loehlin \& Nichols, 1976). Individuals with high cognitive ability (e.g., National Merit Students) express stronger interest in investigative occupations (Pässler et al., 2015). Moreover, in the RIASEC model of vocational interests, investigative and enterprising interests are considered opposing dimensions (Holland, 1997). Thus, compared to the population, participants in the National Merit sample may, on average, have had a lower interest in enterprising (and a higher interest in investigative interests) in the first place. This possibly might have distorted the GFP-enterprising interest relation. Despite these variations in findings, however, study 3 was consistent with the previous two studies in showing a GFP-social interest relationship.

The fact that the GFP-vocational interest relationship showed a relevant heritable component supports the notion that the genes that provide people with a disposition for a higher GFP are probably partially the same genes that push a person towards interest in social (and in this case also investigative) interests. As such, study 3 goes beyond the two previous studies by indicating that a part of the personality-vocational interest relationships is at a rather fundamental level.

The dataset of twins from the National Merit sample had the advantage that we could conduct behavioral genetic analyses. Yet, the sample had a limitation that it was not representative for the population, but consisted of those with very high scores on scholastic aptitude tests. Subsequently, in future research, it would be useful to test the genetic correlation between the GFP and vocational interest again in other, more representative samples.

\section{General Discussion}

In the present set of studies, we examined preferences for occupations and activities by taking into account the GFP. This approach may contribute to the literature in several ways. First, the studies provide information about the nature of the GFP, which is relevant for the more fundamental scientific discussion on the hierarchical structure of personality. Second, the set of studies provide a novel perspective on how personality and vocational interests are related by assuming that the shared variance among personality dimensions should not be simply dismissed (as in previous studies using linear regression analyses) but has explanatory power.

With regard to the former point, across the four samples, a general pattern of findings emerged, indicating that the GFP particularly relates to interest in working with people. This entailed that social and enterprising interests showed the strongest relations with the GFP (studies 1 and 3) and with the broad interest factor of working with people (study 2). The GFP showed consistent and significant phenotypical as well as genetic correlations with social interests.

This pattern of findings partly supports the notion that the GFP is a broad social effectiveness factor. Humans are social by nature, and it is, therefore, clear that getting along with others at work or using social interactions to succeed are common themes in most occupations (Wolfe et al., 1986). Yet, as jobs differ in the extent to which their success and satisfaction depend on such social components, it is reasonable to assume that those people who are more socially effective tend to gravitate toward more socially laden jobs or activities. This assumption was already supported by previous studies on the relationship between emotional intelligence and vocational interests (e.g., Schermer et al., 2015) and, in the present research, has also been extended to the GFP.

The most obvious alternative explanation, namely that the GFP is merely a statistical artifact, method bias, or social desirability factor (Ashton et al., 2009; Bäckström et al., 2009; Connelly \& Chang, 2016) cannot be completely ruled out by the present findings, but may nevertheless be considered substantially less likely for the following reasons. 
First, it does not seem obvious that response bias or social desirability would particularly strongly relate to social occupations. Certain jobs, such as engineer, computer programmer, and rocket scientist, generally have a high status, even though they are not particularly social. Second, if the scores on personality would be strongly influenced by response biases, then it can be logically assumed that such biases remain rather consistent over different measures. The GFP, however, did not strongly correlate with the general factor of vocational interests (profile elevation), which, at least, indicates that they were not prone to similar types of response biases. This finding, in itself, again does not rule out the possibility that one of the general factors is influenced by response bias, but it makes it nevertheless, somewhat less likely, particularly, in the broader context of findings. Third, the relations between the GFP and social interests were found at the genetic level. Although even this latter finding does not fully exclude the possibility of social desirability or response bias (both can also have a genetic component), it does suggest that the GFP-social interest link may be relatively deeply ingrained and have trait-like properties.

Beyond contributing to insight into the nature of the GFP, the present findings also generally encourage a new way of looking at the relationship between personality and vocational interest. In previous research, it has often been assumed that personality dimensions are fundamentally independent of each other, and this assumption has theoretical and methodological implications. Assuming independent traits implies, for example, that one has to establish different - unique - explanations for each relationship between a specific personality dimension and vocational interests (e.g., Larson et al., 2002; Mount et al, 2005). This is not a parsimonious approach.

Two questions that may arise in this context are (1) whether the GFP can provide a unique contribution to explaining vocational interests beyond the specific personality dimensions (e.g., the Big Five), and (2) whether the GFP findings can be explained by the effects of one or two specific traits, such as extraversion and neuroticism.

Regarding the former question, from the perspective of a substantive general factor, a test of its influence beyond lowerorder traits such as the Big Five would not be meaningful. After all, the GFP is assumed to be partially present in each of the specific personality dimensions (Van der Linden et al., 2016). Therefore, controlling for Big Five would mean deleting the true variance of the general factor. One can compare this to testing whether a general factor of cognitive ability $(g$ ) contributes beyond the sub-tests from which it is extracted. This would not make much sense (Jensen, 1998). Doing it the other way around, however, by testing whether the unique variance of specific traits contributes, beyond their shared component, is very informative. In these tests that we conducted in studies 1 and 2, it became clear that the GFP accounts for the lion's share of the relationships between specific personality dimensions and vocational interests. The GFP explained relatively large proportions of the variance in vocational interests with strong social components. The combined unique variances of the mores specific traits often explained less additional variance than the GFP. The comparisons between the GFP and the unique components of traits confirm that the notion of a general factor does not imply that lower-order traits become obsolete. Specific traits may sometimes be better suited to capture individual differences. In line with this, the analyses in studies 1 and 2 show that, in some cases, the unique trait variance can add explained variance beyond the GFP. Yet, if one would ignore the GFP or is unaware of its existence, then one neglects a relevant "part of the picture" when trying to explain what may cause the associations between personality and vocational interests.

Regarding the second question, as the GFP, by definition, reflects the shared variance of the underlying traits, it can never be "just" extraversion or neuroticism (or any other specific trait). This can be confirmed, for example, by looking at the factor loadings of the samples in study 1 . Those reveal that the GFP is not based on the influence of (a combination of) one or two traits, but rather represents a balanced mix of socially desirable or socially effective traits.

\section{Concluding Statements}

Personality and vocational interests are known to overlap (Mount et al., 2005). For example, people who have a tendency for working very systematically and accurately prefer jobs that fit with those tendencies, and people who are good at social interaction or find being with other people highly rewarding prefer social jobs. The present research incorporates the GFP in this line of thinking. People who are generally socially effective-which may be akin to being emotionally intelligent (Van der Linden et al., 2017)—would, on average, not be very shy, antagonistic, unstable, unreliable, or rigid in their social interactions. Thus, high social effectiveness affects one's scores on many of the underlying personality dimensions. This general social effectiveness would also partly manifest itself in higher interests in jobs or activities in which such effectiveness can be put to use to gain satisfaction or success in one's professional career.

Supplementary Information The online version contains supplementary material available at https://doi.org/10.1007/s10869-021-09779-8.

Open Access This article is licensed under a Creative Commons Attribution 4.0 International License, which permits use, sharing, adaptation, distribution and reproduction in any medium or format, as long as you give appropriate credit to the original author(s) and the source, provide a link to the Creative Commons licence, and indicate if changes were made. The images or other third party material in this article are included in the article's Creative Commons licence, unless indicated 
otherwise in a credit line to the material. If material is not included in the article's Creative Commons licence and your intended use is not permitted by statutory regulation or exceeds the permitted use, you will need to obtain permission directly from the copyright holder. To view a copy of this licence, visit http://creativecommons.org/licenses/by/4.0/.

\section{References}

Anglim, J., Morse, G., Dunlop, P. D., Minbashian, A., \& Marty, A. (2019). Predicting trait emotional intelligence from HEXACO personality: Domains, facets, and the general factor of personality. Journal of Personality, 88, 324-338. https://doi.org/10.1111/ jopy. 12493

Ashton, M. C., Lee, K., Goldberg, L. R., \& de Vries, R. E. (2009). Higher-order factors of personality: Do they exist? Personality and Social Psychology Review, 13, 79-91. https://doi.org/10.1177/ 1088868309338467

Bäckström, M., Björklund, F., \& Larsson, M. R. (2009). Five-factor inventories have a major general factor related to social desirability which can be reduced by framing items neutrally. Journal of Research in Personality, 43, 335-344. https://doi.org/10.1016/j. jrp.2008.12.013

Bäckström, M., Björklund, F., Persson, R., \& Costa, A. (2020). Fivefactor personality inventories have a competence-related higherorder factor due to item phrasing. Frontiers in Psychology, 11, 3211. https://doi.org/10.3389/fpsyg.2020.557544

Berings, D., De Fruyt, F., \& Bouwen, R. (2004). Work values and personality traits as predictors of enterprising and social vocational interests. Personality and Individual Differences, 36(2), 349-364. https://doi.org/10.1016/S0191-8869(03)00101-6.

Blackwell, T., \& Case, J. (2008). Test review - Strong Interest Inventory, Revised Edition. Rehabilitation Counseling Bulletin., 51, 122-126. https://doi.org/10.1177/0034355207311350

Bose, C. E., \& Rossi, P. H. (1983). Gender and jobs: Prestige standings of occupations as affected by gender. American sociological review, 316-330. https://doi.org/10.2307/2095225

Chamorro-Premuzic, T. (2007). BPS textbooks in psychology: Personality and individual differences. Blackwell Publishing.

Chang, L., Connelly, B. S., \& Geeza, A. A. (2012). Separating method factors and higher order traits of the Big Five: A meta-analytic multitrait-multimethod approach. Journal of Personality and Social Psychology, 102, 408. https://doi.org/10.1037/a0025559

Connelly, B. S., \& Chang, L. (2016). A meta-analytic multitrait multirater separation of substance and style in social desirability scales. Journal of Personality, 84, 319-334. https://doi.org/10.1111/jopy. 12161

Credé, M., \& Harms, P. D. (2015). 25 years of higher-order confirmatory factor analysis in the organizational sciences: a critical review and development of reporting recommendations. Journal of Organizational Behavior, 36(6), 845-872. https://doi.org/10. 1002/job.2008.

Donnay, D. A. C. (1997). E.K. Strong's legacy and beyond: 70 years of the Strong Interest Inventory. The Career Development Quarterly., 46, 2-22. https://doi.org/10.1002/j.2161-0045.1997.tb00688.x

Duncan, O. D. (1961). A socioeconomic index for all occupations. Class: Critical Concepts, 1, 388-426.

Dunkel, C. S. (2013). The general factor of personality and general intelligence: Evidence for substantial association. Intelligence, 41 , 423-427. https://doi.org/10.1016/j.intell.2013.06.010

Dunkel, C. S., De Baca, T. C., Woodley, M. A., \& Fernandes, H. B. (2014). The general factor of personality and general intelligence:
Testing hypotheses from differential-K, life history theory, and strategic differentiation-integration effort. Personality and Individual Differences, 61, 13-17. https://doi.org/10.1016/j.paid.2013. 12.017

Dunkel, C. S., \& Van der Linden, D. (2014). Evidence for the general factor of personality as social-effectiveness. Personality and Individual Differences, 64, 147-151. https://doi.org/10.1016/j.paid. 2014.02.030

Dunkel, C. S., \& Cabeza de Baca, T. (2016). Replication of the association between general intelligence and the general factor of personality using the California Child Q-set. Intelligence, 56, 35-37. https://doi.org/10.1016/j.intell.2016.02.007

Dunkel, C. S., van der Linden, D., Brown, N. A., \& Mathes, E. W. (2016). Self-report based general factor of personality as sociallydesirable responding, positive self-evaluation, and social-effectiveness. Personality and Individual Differences, 92, 143-147. https://doi.org/10.1016/j.paid.2015.12.034

Figueredo, A. J., \& Rushton, J. P. (2009). Evidence for shared genetic dominance between the general factor of personality, mental and physical health, and life history traits. Twin Research and Human Genetics, 12(6), 555-563. https://doi.org/10.1375/twin.12.6.555.

Figueredo, A. J., Vasquez, G., Brumbach, B. H., \& Schneider, S. M. (2004). The heritability of life history strategy: The k-factor, covitality, and personality. Social Biology, 51, 121-143. https://doi. org/10.1080/19485565.2004.9989090

Flanagan, J. C. (1962). Design for a study of American youth

Fuller, B. E., Holland, J. L., \& Johnston, J. A. (1999). The relation of profile elevation in the Self-Directed Search to personality variables. Journal of Career Assessment, 7(2), 111-123. https://doi. org/10.1177/106907279900700202.

Gosling, S. D., Rentfrow, P. J., \& Swann, W. B., Jr. (2003). A very brief measure of the Big-Five personality domains. Journal of Research in Personality, 37, 504-528. https://doi.org/10.1016/ S0092-6566(03)00046-1

Gottfredson, G. D., \& Jones, E. M. (1993). Psychological meaning of profile elevation in the Vocational Preference Inventory. Journal of Career Assessment, 1, 35-49. https://doi.org/10.1177/10690 7279300100105

Harmon, L. W., Hansen, J. C., Borgen, F. H., \& Hammer, A. L. (1994). Strong interest inventory: applications and technical guide. Stanford University Press.

Hirschi, A., \& Läge, D. (2007). The relation of secondary students' career-choice readiness to a six-phase model of career decision making. Journal of Career Development, 34, 164-191. https://doi. org/10.1177/0894845307307473

Holland, J. L., Powell, A. B., \& Fritzsche, B. A. (1994). The selfdirected search $(S D S)$. Odessa, FL: Psychological Assessment Resources.

Holland, J. L. (1997). Making vocational choices: A theory of vocational personalities and work environments. Psychological Assessment Resources

Holtrop, D., Born, M. P., \& de Vries, R. E. (2018). Perceptions of vocational interest: Self-and other-reports in student-parent dyads. Journal of Career Assessment, 26, 258-274. https://doi.org/10. $1177 / 1069072717692745$

Hu, L. T., \& Bentler, P. M. (1999). Cutoff criteria for fit indexes in covariance structure analysis: Conventional criteria versus new alternatives. Structural Equation Modeling: A Multidisciplinary Journal, 6, 1-55. https://doi.org/10.1080/10705519909540118

Gerlach, M., Farb, B., Revelle, W., \& Amaral, L. A. N. (2018). A robust data-driven approach identifies four personality types across four large data sets. Nature Human Behaviour, 2, 735. https://doi.org/ 10.1038/s41562-018-0419-Z

Jensen, A. R. (1998). The g factor: The science of mental ability (Vol. 648). Praeger. 
Keller, M. C., Howrigan, D. P., Simonson, M. A. (2010), Theory and methods in evolutionary behavioral genetics. In D. M. Buss \& P. $\mathrm{H}$. Hawley PH (Eds.), The evolution of personality and individual differences (pp. 280-302). Oxford University Press. https://doi. org/10.1093/acprof:oso/9780195372090.001.0001.

Kendler, K. S., Neale, M. C., Kessler, R. C., Heath, A. C., \& Eaves, L. J. (1993). A test of the equal-environment assumption in twin studies of psychiatric illness. Behavior Genetics, 23, 21-27. https://doi.org/10.1007/BF01067551

Larson, L. M., Rottinghaus, P. J., \& Borgen, F. H. (2002). Meta-analyses of Big Six interests and Big Five personality factors. Journal of Vocational Behavior, 61, 217-239. https://doi.org/10.1006/ jvbe. 2001.1854

Loehlin, J. C., \& Nichols, R. C. (1976). Heredity, environment, and personality: A study of 850 sets of twins. University of Texas Press.

Loehlin, J. C. (2011). Correlation between general factors for personality and cognitive skills in the National Merit twin sample. Journal of Research in Personality, 45, 504-507. https://doi.org/10.1016/j. jrp.2011.06.011

Loehlin, J. C., \& Horn, J. M. (2012). How general across inventories is a general factor of personality? Journal of Research in Personality, 46, 258-263. https://doi.org/10.1016/j.jrp.2012.02.003

Lo, M. T., Hinds, D. A., Tung, J. Y., Franz, C., Fan, C. C., Wang, Y., ... \& Chen, C. H. (2017). Genome-wide analyses for personality traits identify six genomic loci and show correlations with psychiatric disorders. Nature genetics, 49, 152-156. https://doi.org/ 10.1038/ng. 3736

McKay, D. A., \& Tokar, D. M. (2012). The HEXACO and five-factor models of personality in relation to RIASEC vocational interests. Journal of Vocational Behavior, 81, 138-149. https://doi.org/10. 1016/j.jvb.2012.05.006

Mount, M. K., Barrick, M. R., Scullen, S. M., \& Rounds, J. (2005). Higher-order dimensions of the big five personality traits and the big six vocational interest types. Personnel Psychology, 58, 447478. https://doi.org/10.1111/j.1744-6570.2005.00468.x

Musek, J. (2007). A general factor of personality: Evidence for the Big One in the five-factor model. Journal of Research in Personality, 41, 1213-1233. https://doi.org/10.1016/j.jrp.2007.02.003

Musek (2017). The general factor of personality. Academic Press

Nye, C. D., Su, R., Rounds, J., \& Drasgow, F. (2012). Vocational interests and performance: A quantitative summary of over 60 years of research. Perspectives on Psychological Science, 7, 384-403. https://doi.org/10.1177/1745691612449021

Oltmanns, J. R., Smith, G. T., Oltmanns, T. F., \& Widiger, T. A. (2018). General factors of psychopathology, personality, and personality disorder: Across domain comparisons. Clinical Psychological Science, 6, 581-589. https://doi.org/10.1177/2167702617750150

Oshio, A., Taku, K., Hirano, M., \& Saeed, G. (2018). Resilience and Big Five personality traits: A meta-analysis. Personality and Individual Differences, 127, 54-60. https://doi.org/10.1016/j.paid. 2018.01.048

Pässler, K., Beinicke, A., \& Hell, B. (2015). Interests and intelligence: A meta-analysis. Intelligence, 50, 30-51. https://doi.org/10.1016/j. intell.2015.02.001

Pelt, D. H., van der Linden, D., Dunkel, C. S., \& Born, M. P. (2017). The general factor of personality and job performance: Revisiting previous meta-analyses. International Journal of Selection and Assessment, 25, 333-346. https://doi.org/10.1111/ijsa.12188

Plomin, R., DeFries, J. C., McClearn, G. E., \& McGuffin, P. (Eds.). (2008). Behavioral genetics (5th ed.). Worth.

Pozzebon, J., Damian, R. I., Hill, P., Lin, Y., Lapham, S., \& Roberts, B. W. (2013). Establishing the validity and reliability of the Project Talent Personality Inventory. Frontiers in Psychology, 4, 968. https://doi.org/10.3389/fpsyg.2013.00968
Power, R. A., \& Pluess, M. (2015). Heritability estimates of the Big Five personality traits based on common genetic variants. Translational Psychiatry, 5, e604-e604. https://doi.org/10.1038/tp. 2015.96

Prediger, D. J. (1998). Is interest profile level relevant to career counseling? Journal of Counseling Psychology, 45, 204. https://doi. org/10.1037/0022-0167.45.2.204

Revelle, W., \& Wilt, J. (2013). The general factor of personality: A general critique. Journal of Research in Personality, 47, 493-504. https://doi.org/10.1016/j.jrp.2013.04.012

Rosenbloom, J. L., \& Ash, R. A. (2009). Professional worker career experience survey (PWCES) data and metadata

Rushton, J. P., Bons, T. A., \& Hur, Y. M. (2008). The genetics and evolution of the general factor of personality. Journal of Research in Personality, 42, 1173-1185. https://doi.org/10.1016/j.jrp.2008. 03.002

Rushton, J. P., \& Irwing, P. (2011). The general factor of personality: Normal and abnormal. The Wiley-Blackwell handbook of individual differences, 132-161. https://doi.org/10.1002/9781444343 120.ch5

Schermer, J. A., Petrides, K. V., \& Vernon, P. A. (2015). On the genetic and environmental correlations between trait emotional intelligence and vocational interest factors. Twin Research and Human Genetics, 18, 134-137. https://doi.org/10.1017/thg.2014.87

Spector, P. E., \& Brannick, M. T. (2011). Methodological urban legends: The misuse of statistical control variables. Organizational Research Methods, 14, 287-305. https://doi.org/10.1177/10944 28110369842

Su, R., Rounds, J., \& Armstrong, P. I. (2009). Men and things, women and people: A meta-analysis of sex differences in interests. Psychological Bulletin, 135, 859. https://doi.org/10.1037/a0017364

$\mathrm{Su}, \mathrm{R}$ (2012). The power of vocational interests and interest congruence in predicting career success. Dissertation. University of Illinois. Urbana, Illinois. http://hdl.handle.net/2142/34329. (retrieved in December 2019).

Van der Linden, D., Dunkel, C. S., \& Petrides, K. V. (2016). The General Factor of Personality (GFP) as social effectiveness: Review of the literature. Personality and Individual Differences, 101, 98-105. https://doi.org/10.1016/j.paid.2016.05.020

Van der Linden, D., Dunkel, C. S., \& Wu, P. (2021). Is there a meaningful general factor of personality? The Spanish Journal of Psychology, 24, e9. https://doi.org/10.1017/SJP.2021.2

Van der Linden, D., Oostrom, J. K., Born, M. P., Van der Molen, H. T., \& Serlie, A. W. (2014). Knowing what to do in social situations. Journal of Personnel Psychology. https://doi.org/10.1027/ 1866-5888/a000113.

Van der Linden, D., Pekaar, K. A., Bakker, A. B., Schermer, J. A., Vernon, P. A., Dunkel, C. S., \& Petrides, K. V. (2017). Overlap between the general factor of personality and emotional intelligence: A meta-analysis. Psychological Bulletin, 143, 36-52. https://doi.org/10.1037/bul0000078

Van der Linden, D., Schermer, J. A., de Zeeuw, E., Dunkel, C. S., Pekaar, K. A., Bakker, A. B., Vernon, P. A., \& Petrides, K. V. (2018). Overlap between the general factor of personality and trait emotional intelligence: A genetic correlation study. Behavior Genetics, 48, 147-154. https://doi.org/10.1007/ s10519-017-9885-8

Van der Linden, D., Scholte, R. H., Cillessen, A. H., te Nijenhuis, J., \& Segers, E. (2010b). Classroom ratings of likeability and popularity are related to the Big Five and the general factor of personality. Journal of Research in Personality, 44, 669-672. https://doi.org/ 10.1016/j.jrp.2010.08.007

Van der Linden, D., te Nijenhuis, J., \& Bakker, A. B. (2010a). The general factor of personality: A meta-analysis of Big Five intercorrelations and a criterion-related validity study. Journal of 
Research in Personality, 44, 315-327. https://doi.org/10.1016/j. jrp.2010.03.003

Van der Linden, D., te Nijenhuis, J., Cremers, M., \& van de Ven, C. (2011). General factors of personality in six datasets and a criterion-related validity study at the Netherlands armed forces. International Journal of Selection and Assessment, 19(2), 157-169. https://doi.org/10.1111/j.1468-2389.2011.00543.x.

Van Iddekinge, C. H., Roth, P. L., Putka, D. J., \& Lanivich, S. E. (2011). Are you interested? A meta-analysis of relations between vocational interests and employee performance and turnover. Journal of Applied Psychology, 96, 1167. https://doi.org/10.1037/ a0024343

Veselka, L., Schermer, J. A., Petrides, K. V., \& Vernon, P. A. (2009). Evidence for a heritable general factor of personality in two studies. Twin Research and Human Genetics, 12, 254-260. https://doi. org/10.1375/twin.12.3.254
Wolfe, R. N., Lennox, R. D., \& Cutler, B. L. (1986). Getting along and getting ahead: Empirical support for a theory of protective and acquisitive self-presentation. Journal of Personality and Social Psychology, 50, 356. https://doi.org/10.1037/0022-3514.50.2.356

Wu, P., Van der Linden, D., Dunkel, C. S., van Vugt, M., \& Han, Q. (2020). Emerging leadership and the general factor of personality (GFP): A quasi-experimental test of an evolutionary prediction. Evolutionary Behavioral Sciences. https://doi.org/10.1037/ebs00 00234.

Publisher's Note Springer Nature remains neutral with regard to jurisdictional claims in published maps and institutional affiliations. 